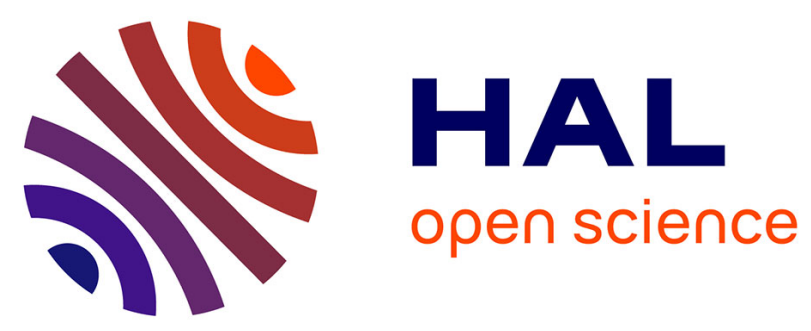

\title{
Expression and functionality of Toll- and RIG-like receptors in HepaRG cells
}

Souphalone Luangsay, Malika Ait-Goughoulte, Maud Michelet, Océane

Floriot, Marc Bonnin, Marion Gruffaz, Michel Rivoire, Simon Fletcher, Hassan Javanbakht, Julie Lucifora, et al.

\section{To cite this version:}

Souphalone Luangsay, Malika Ait-Goughoulte, Maud Michelet, Océane Floriot, Marc Bonnin, et al.. Expression and functionality of Toll- and RIG-like receptors in HepaRG cells. Journal of Hepatology, 2015, 63 (5), pp.1077-1085. 10.1016/j.jhep.2015.06.022 . hal-03315724

\section{HAL Id: hal-03315724 \\ https://hal.science/hal-03315724}

Submitted on 12 Aug 2021

HAL is a multi-disciplinary open access archive for the deposit and dissemination of scientific research documents, whether they are published or not. The documents may come from teaching and research institutions in France or abroad, or from public or private research centers.
L'archive ouverte pluridisciplinaire HAL, est destinée au dépôt et à la diffusion de documents scientifiques de niveau recherche, publiés ou non, émanant des établissements d'enseignement et de recherche français ou étrangers, des laboratoires publics ou privés. 


\title{
Expression and Functionality of Toll- and RIG-like receptors in HepaRG Cells
}

\author{
Souphalone Luangsay ${ }^{1,2,5,{ }^{*}}$, Malika Ait-Goughoulte ${ }^{1,2,5,{ }^{*}}$, Maud Michelet ${ }^{1,2}$, Océane \\ Floriot $^{1,2}$, Marc Bonnin ${ }^{1,2}$, Marion Gruffaz ${ }^{1,2}$, Michel Rivoire ${ }^{3,4}$, Simon Fletcher, \#, \\ Hassan Javanbakht ${ }^{5}$, Julie Lucifora ${ }^{1,2}$, Fabien Zoulim $^{1,2,6,7, \pi}$ and David Durantel ${ }^{1,2, \pi}$ \\ 1 INSERM U1052, CNRS UMR_5286, Cancer Research Centre of Lyon (CRCL), 69008 Lyon, France; \\ 2 University of Lyon, Université Claude Bernard (UCBL), UMR_S1052, 69008 Lyon, France; \\ ${ }^{3}$ Centre Léon Bérard (CLB), 69008 Lyon, France; \\ ${ }^{4}$ INSERM U1032, 69003 Lyon, France; \\ ${ }^{5}$ Hoffmann-La Roche Ltd, Basel, Switzerland; \\ ${ }_{7}^{6}$ Hospices Civils de Lyon (HCL), 69002 Lyon, France; \\ ${ }^{7}$ Institut Universitaire de France (IUF), 75005 Paris, France; \\ \# Present address: Gilead Sciences, CA Foster city, USA.; \\ * Contributed equally; \\ "Contributed equally.
}

\section{Contacts:}

David Durantel (david.durantel@inserm.fr) or Fabien Zoulim (fabien.zoulim@inserm.fr) Address: INSERM U1052, 151 cours Albert Thomas, 69003 Lyon, France

Phone: + 33472681970

Fax : +33472681971

\section{Metrics:}

Electronic word count: 4942

Number of main figures: 6

Number of Table: 1

Supplementary figures : 3

\section{List of abbreviations in the order of appearance :}

Primary human hepatocyte $(\mathrm{PHH})$; toll-like receptor (TLR); retinoic acid-inducible gene 1 (RIG-I) ; RIG-like receptor (RLR) ; reverse transcription (RT) ; quantitative polymerase chain reaction (qPCR); fluorescence-activated cell sorting (FACS); interleukin-6 (IL-6); interferon-gamma-inducible protein-10 (IP-10); interferon (IFN); hepatitis B virus (HBV); melanoma differentiation-associated gene 5 (MDA-5); Hepatitis A virus (HAV); hepatitis E virus (HEV); hepatitis D virus (HDV); hepatitis C; world health organization (WHO); hepatocellular carcinoma (HCC); pathogen recognition receptor (PRR); C-type lectin receptor CLR); NOD-like receptor (NLR); deoxy-ribonucleic acid (DNA); pathogenassociated molecular pattern (PAMP); double-stranded ribonucleic acid (dsRNA); sodium taurocholate cotransporting polypeptide (NTCP); differentiated HepaRG (dHepaRG); american type culture collection (ATCC) ; dimethysulfoxide (DMSO) ; complementary DNA (cDNA); cycle threshold (CT) ; lipoteichoic acid (LTA), lipopolyipopolysaccharide (LPS) ; oligonucleotie (ODN); low molecular weight (LMW); Ethylenediaminetetraacetic acid (EDTA) ; sodium dodecyl sulfate- polyacrylamide gel electrophoresis (SDS-PAGE) ; hepatitis $B$ « $\mathrm{e}$ » antigen ( $\mathrm{HBeAg})$; hepatitis $\mathrm{B}$ « $\mathrm{s}$ » antigen (HBsAg); enzyme-linked immunosorbent assay (ELISA) ; proliferative HepaRG (pHepaRG) ; nuclear factorkappa B (NF-кB) ;

Key Words: pathogen recognition receptor (PRR), toll-like receptor (TLR), hepatocyte, hepatitis $B$ virus (HBV), antiviral activity 
Conflict of Interest: DD and FZ have received research grants from Hoffmann-LaRoche; SF and HJ was/is employees at Hoffmann-La-Roche; SL and MAG were postdoctoral fellows at INSERM at the time the research was performed, but are now employees at Hoffmann-La- Roche.

Authors contribution: SL, MAG, MM, OF, MG, MB, JL, DD performed experiments; SL, MAG, SF, HJ, FZ, DD designed experiments; SL, MAG, MM, OF, MB, JL, DD analysed results and drawn figures; SL, MAG, FZ, DD wrote the manuscript. ${ }^{*}$ contributed equally, "contributed equally

Acknowledgements and financial support: The authors would like to thank Lydie Lefrançois and Judith Fresquet for the isolation of primary human hepatocytes, as well as the staff from Pr Michel Rivoire's surgery room for providing us with liver resection. This work was supported by grants from ANRS (French national agency for research on AIDS and viral hepatitis; several grants from CSS4), FINOVI (Foundation for innovation in infectiology; project call $n^{\circ} \# 4$ ), FRM (Foundation for medical research; DEQ20110421327), Hoffmann-LaRoche Ltd (Switzerland division) and by INSERM core grants. This work was also supported by the DEVweCAN LABEX (ANR-10-LABX-0061) of the "Universite de Lyon", within the program "Investissements d'Avenir" (ANR-11-IDEX-0007) operated by the French National Research Agency (ANR). 


\section{Abstract}

Background \& Aims: HepaRG cells are considered as the best surrogate model to primary human hepatocyte $(\mathrm{PHH})$ culture to investigate host-pathogen interactions. Yet their innate immune functions remain unknown. In this study, we studied the expression and functionality of Toll-like (TLR) and retinoic-acid-inducible gene-1 (RIG-I)-like (RLR) receptors in these cells.

Methods: Gene and protein expression levels of TLR-1 to 9 and RLR in HepaRG were mainly compared to $\mathrm{PHH}$, by RT-qPCR, FACS, and Western Blotting. Their functionality was assessed, by measuring the induction of toll/rig-like themselves and several target innate gene expressions, as well as the secretion of IL-6, IP-10, and type-I interferon (IFN), upon agonist stimulation. Their functionality was also evidenced, by measuring the antiviral activity of some TLR/RLR agonists against hepatitis B virus (HBV) infection.

Results: The basal gene and protein expression profile of TLR/RLR in HepaRG cells was similar to $\mathrm{PHH}$. Most of receptors, except for TLR-7 and 9, were expressed as proteins and functionally active as evidenced by the induction of some innate genes, as well as by secretion of IL-6 and IP-10, upon agonist stimulation. The highest levels of IL-6 and IP-10 secretion were obtained by TLR-2 and TLR-3 agonisation respectively. The highest preventive anti-HBV activity was obtained following TLR-2, TLR-4 or RIG-I/MDA-5 stimulations, which correlated with their high capacity to produce both cytokines.

Conclusions: Our results indicate that HepaRG cells express a similar pattern of functional TLR/RLR as compared to $\mathrm{PHH}$, thus qualifying HepaRG cells as a surrogate model to study pathogen interactions with hepatocyte innate system. 
The liver is targeted by several important human pathogens, including plasmodium falciparum or hepatotropic viruses [1]. Among them, Hepatitis A virus (HAV) and HEV do not usually establish persistent infections, whereas HBV, HDV and HCV may evolve toward chronicity [1]. The high number of chronic carriers, around 240 million for HBV (WHO data) and 130 million for HCV worldwide, account for the rapid increase in the incidence of hepatocellular carcinoma (HCC) [2]. Pathogenesis of

Infection of cells by microorganisms leads to the activation of the host inflammatory defense response through the initial sensing of pathogen mediated by innate pattern recognition receptors (PRR) [4]. PRR are mainly represented by Tolllike receptors (TLR), C-type lectin receptors (CLR), RIG-I-like receptors (RLR) and NOD-like receptors (NLR). In addition, intracellular DNA sensors are proposed as new types of PRR [5]. To date, ten functional TLR have been identified in human viruses can activate TLR pathways [8]. Cells also express cytoplasmic RNA helicases such as RIG-I (Retinoic-acid Inducible Gene-I) and MDA-5 (melanomadifferentiation-associated gene-5) that function as an alternative class of PRR through the recognition of dsRNA produced during viral replication. 
Viruses can evade IFN response and recent studies have increased our

understanding of the underlying molecular mechanisms of inhibitions [9]. Following infection, viruses can induce complex intracellular events that affect many components of host signaling pathways to its own benefits $[10,11]$. Elucidating the strategies that are used by viruses to inhibit host responses is important for the understanding of the mechanism(s) by which viruses can establish persistent infections and to design strategies to unlock this inhibition for therapeutic purposes.

Although the expression of some PRR genes was shown in human liver tissue and $\mathrm{PHH}$, the expression and functional activity of a wide spectrum of PRR on human hepatocytes remains poorly defined $[12,13]$. Transformed hepatic cell lines such as HepG2 and Huh7 are commonly used to study hepatotropic viruses life cycle and early host/virus interaction, however, in terms of innate immunity, these cells differ from $\mathrm{PHH}$ in that they do not have fully functional IFN pathways [14, 15] and display profound defect in PRR signaling [16]. Beside recently developed models based hepatoma cells overexpressing NTCP [17], or on the complex use of induced pluripotent cells (iPS) [18], only freshly prepared primary human hepatocytes and the hepatocyte-like HepaRG cells can support a complete HBV and HDV life cycle, including the early events of infection [19-21].

HepaRG cells are bipotent liver progenitor cells that differentiate into both cholangiocyte-like and hepatocyte-like cells in culture. Throughout differentiation, HepaRG cells evolve from a homogeneous dedifferentiated, depolarized epithelial phenotype showing no specific organization to a structurally well-defined and polarized monolayer closely resembling those formed in $\mathrm{PHH}$ culture [22-24]. This cell line represents an in vitro human model for hepatocytic differentiation and was shown to be functional for IFN signaling [25]. However, the functionality of TLRs/RLRs this cell line has not been described so far. 


\section{Material and Methods}

\section{Cell culture and HBV infection}

HepaRG cells were cultured and differentiated in presence of DMSO (cell culture grade, Sigma) as previously described [20]. Primary human hepatocytes $(\mathrm{PHH})$ were freshly prepared, as previously described and maintained in same media as dHepaRG [26]. Huh7 and HepG2 (ATCC) cells were also maintained in complete William's medium and cultured in presence of DMSO for three days before RNA extraction. The transfection of siRNA (SMARTpool ${ }^{\mathrm{TM}}$ from Darmacon/GE) into dHeppaRg or $\mathrm{PHH}$ cells was performed using Darmafect-1 reagent, as recommended by provider (Darmacon/GE). HBV recombinant virus (i.e. inoculum) was produced in HepG2.2.15 cells and differentiated HepaRG infected as previously described [27].

\section{Nucleic acid extraction and $R T-q P C R / q P C R$}

Total RNA was extracted from cells with the NucleoSpin RNA II kit according to manufacturer's instructions (Macherey-Nagel). RNA reverse transcription was performed using the Superscript III RT (Life Technologies). cDNA was then analyzed by qPCR with the "Express SYBR GreenER ${ }^{\mathrm{TM}}$ qPCR SuperMix Universal" (Invitrogen). RNA expression level was determined using the comparative cycle threshold (Ct) method, where the amount of target DNA was normalized to housekeeping genes $r p / p 0$ and $\beta$-actin CDNA $\left(2^{-\Delta C t}\right)$. When cells were stimulated with ligands the amount of target DNA was normalized to housekeeping genes and to the unstimulated control cDNA $\left(2^{-\Delta \Delta C t}\right)$. Primers used for the qPCR step are presented in Table 1. Total DNA was extracted from HepaRG using the MasterPure ${ }^{\mathrm{TM}}$ Complete DNA/RNA Purification Kit (Epicentre). Quantitative PCR for intracellular HBV DNA was performed as indicated above using HBV specific primers.

\section{Toll-and RIG-like receptor agonists and stimulation}


All agonists were purchased from InvivoGen and used according to provider's recommendation. Pam3CSK4, LTA, Poly(I:C)-LMW, LPS, Flagellin (FLA-BS), FSL-1, Imiquimod (R837) or CL264, R848, ssRNA40/lyoVec ${ }^{\mathrm{TM}}$, CpG ODN-2395 (class-C + CpG control), Poly(I:C)-LMW/LyoVec ${ }^{\top M}$ were respectively used to stimulate/engage TLR-1/2, TLR-2, TLR-3, TLR-4, TLR-5, TLR-2/6, TLR-7, TLR7/8, TLR-8, TLR-9, and RIG-I/MDA-5. The concentrations used are indicated in the figure legends.

\section{Flow cytometry analysis}

To detect TLR expression, $10^{6}$ HepaRG or PHH cells were fixed with paraformaldehyde (2\%; Sigma) and permeabilized with saponin (0.25\%; Sigma). After saturation (saponin $0.25 \%$, fraction-V albumin $3 \%$; Sigma), cells were stained with purified anti-human TLR-2, 4, 5, 6 (sc-73181, sc-52062, sc-57461, sc-30001; Santa Cruz), anti-human TLR-7, 8, 9 (Alexis Biochemicals (ALX-210-874-C100, ALX804-376-C100) or Abcam (ab184943, ab85859, ab45371)), or anti-human TLR-3 (mAb hTLR-3; Invivogen), followed by incubation with the appropriate secondary antibody conjugated to Alexa Fluor 488 (Invitrogen). For double staining, either anticytochrome P450-3A4 antibody (ab135813; Abcam) or anti-cytochrome P450-3A1 (ab22724; Abcam), which specifically stain hepatocytes and not cholangiocytes (Sup.Fig. 1) were used in combination with anti-PRR antibodies from either mouse or rabbit origin. Cells were analyzed using a FACScalibur flow cytometer and analyzed using CellQuestPro software (BD Biosciences).

\section{Western blot analysis}

Cells were harvested in lysis buffer $(140 \mathrm{mM} \mathrm{NaCl}, 10 \mathrm{mM}$ Tris $\mathrm{pH} 7.6,1 \mathrm{mM}$ EDTA, $1 \%$ Triton X-100, $0.05 \%$ sodium dodecyl sulfate, $1 \mathrm{x}$ protease inhibitor cocktail 5Roche). Clarified lysates were subjected to SDS-PAGE and Western blot transfer to nitrocellulose membranes (Millipore). Membranes were probed with anti-RIG-I, antiMDA5, or anti-TLR2 antibodies (Alexis Biochemicals and Santa Cruz) followed by 
peroxidase-conjugated secondary antibodies (Life Technologies) and detection by

206 chemiluminescence (Pierce). Anti-actin (Sigma) was used as a loading control.

\section{Enzyme-linked immunoassay for IL-6, IP-10, and secreted HBV antigens}

Supernatant from stimulated culture was harvested and assayed for IL-6 and IP10 protein by ELISA using the human IL-6 or human IP10 assay kit according to the manufacturer's protocol (Invitrogen). Cut-offs for these ELISA were $2.5 \mathrm{pg} / \mathrm{mL}$. HBeAg and HBsAg were detected in the supernatant of infected HepaRG by ELISA

212 using Autobio kits (Autobio, China). Cut-offs for these ELISA were respectively 1

$213 \mathrm{NCU} / \mathrm{mL}$ (i.e. $1 \mathrm{NCU} \approx 13 \mathrm{ng}$ ) and $2.5 \mathrm{ng} / \mathrm{mL}$.

\section{Statistical analysis}

Statistical analysis was performed using the nonparametric Mann-Whitney tests using the GraphPad Prism software. For all tests, a p value $\leq 0.05\left(^{*}\right)$ was considered as significant. 
Analysis of TLR and RLR RNA expression in dHepaRG cells and PHH at RNA level

Differentiated HepaRG cells, $\mathrm{PHH}$, as well as DMSO-partially re-differentiated Huh7 [28] and HepG2 [29] cells were investigated for total RNA expression levels for tIr-2 to $t / r-10$, as well as $r i g-I$ and $m d a-5$. All tIrs were similarly expressed in dHepaRG and $\mathrm{PHH}$, whereas levels of expression were significantly lower in the two transformed hepatoma cell lines, except for t/r-8 expression, which was slightly higher in the latters. Rig-I and mda-5 were well expressed in all cell types, but more expressed in $\mathrm{PHH}$ as compared to other cells. T/r-7, 8, 9, and $t / r-10$ were less expressed than other sensors in both dHepaRG and PHH (Fig. 1A and 1B). The expression level of these PRR was further analyzed according to the HepaRG differentiation status (Fig.1C). Differentiated HepaRG cells expressed slightly more t/r-2, 3, 4 and t/r-6 as compared to proliferative HepaRG (pHepaRG) whereas the expression level of the other sensors tested was not highly significantly changed in dHepaRG versus pHepaRG.

\section{Analysis of TLR and RLR protein production in HepaRG cells and PHH}

TLR protein expression in pHepaRG and dHepaRG was further analyzed (Fig. 2A/2B). FACS analysis showed that all TLR (TLR-2 to 9, with TLR-6 being less expressed) were produced in both proliferative and differentiated HepaRG cells (Fig. 2A), and a positive reactivity was also obtained for TLR-7, 8, and 9, whose expression at RNA level was very low. The expression of TLR in dHepaRG cells was found qualitatively similar, but quantitatively slightly higher as compared to $\mathrm{PHH}$ (two different batches) (Fig. 2B and Sup.Fig. 2), whereas the RNA levels were similar suggesting differences in post-transcriptional or post-translational regulations. The expression of the cytosolic sensors RIG-I and MDA-5 was analyzed by western-blot 
in PHH and differentiated HepaRG cells. Both sensors could be detected at basal

247 level, but were highly expressed following cell stimulation (24h) with IFN- $\alpha$ (1000

$248 \mathrm{UI} / \mathrm{ml}$ ) (Fig. 2C). Since differentiation of HepaRG cells leads to a mixture of hepatocyte- and cholangiocyte-like cells, we sought to determine whether expression of PRR would be differentially distributed in each cell type by flow cytometry using a double staining with antibodies directed against selected TLR and hepatocyte specifically-expressed P450 cytochromes. We found that the selected TLR were more expressed in hepatocyte-like cells, as compared to cholangiocyte-like ones (Fig. 2D).

Inducibility of cytokine RNA expression upon stimulation with TLR/RLR prototypic ligands/agonists

Differentiated HepaRG cells were stimulated for 2, 4, 8 and $16 \mathrm{~h}$ by indicated TLR/RLR cognate ligands at concentrations indicated in legend. This stimulation could induce the expression of the pro-inflammatory cytokine gene (IL-6), the type I and type III IFNs (IFNa, $\beta$ and $\lambda$ ) and interferon stimulated genes, ISGs (ISG56). With the exception of TLR7 and 9 ligands, all cognate ligands could induce IL-6 gene expression at the concentration tested (Fig. 3A, panel IL-6). A strong IL-6 induction was observed after $16 \mathrm{~h}$ of stimulation for TLR-2, 3, 4, 5, 6, RIG-I/MDA-5, whereas an induction was observed for TLR-8 after $2 \mathrm{~h}$ of stimulation only which returned to baseline very rapidly. Because production of type-I interferons, in particular IFN- $\beta$, is one of the first cellular antiviral defenses, we tested whether this gene was activated at RNA level in HepaRG cells after some TLR/RLR stimulations. Indeed interferon- $\beta$ gene expression was found induced after stimulation by some cognate ligands (Fig. 3A, panel IFN- $\beta$ ). IFN- $\beta$ gene moderately increased after stimulation with TLR-3, 7, 8 and 9 ligands, but strongly increased after stimulation with RIG-I/MDA-5 ligands. It is

271 worth noting that the concentration of poly(I:C)-LMW/lyoVec ${ }^{T M}(1 \mu \mathrm{g} / \mathrm{mL})$ used in these experiments was shown to be slightly toxic when multiple dosing were used for 
antiviral studies; this led to a readjustment of the concentration in experiments presented hereafter. Stimulation of TLR-3, 7, 9 and RIG-I/MDA-5 also slightly induced IFN- $\alpha$ expression (Fig. 3A, panel IFN- $\alpha$ ). Type-III IFN expression has been shown to depend on the same stimulations, i.e. viral infection or ds-RNA ligands, and signal transduction pathway, as those inducing type I IFN expression in epithelial cells [30]. IL-28B (IFN- $\lambda 3$ ) expression was only induced by TLR-3 or RIG-I/MDA-5 stimulations, although the kinetic of activation was different (i.e. earlier for TLR-3) (Fig. 3A, panel IL-28B). The induction of IL-29 (IFN- $\lambda 1$ ) was unexpectedly lower than that of IL-28B (Fig. 3A, panel IL-29). The activation of all IFN transcripts was associated to the activation of prototypic ISGs such as ISG56 induced after TLR-3 stimulation and RIG-I/MDA-5.

In PHH, low-level of gene activation was also observed with TLR-7/9-L (Fig. 4A), but as $\mathrm{PHH}$ cultures are not completely pure, we cannot exclude that residual activation was due to the presence of other liver cells.

\section{Secretion profile of IL-6, IP-10, and type-I IFN after stimulation with TLR/RLR} prototypic ligands

The cell culture supernatants of HepaRG cells were first tested for the production of IL-6 and IP-10 following a 24h TLR/RLR stimulation with increasing doses of prototypic ligands (Fig. 3B/C). Basically, all TLR/RLR ligands tested, but not TLR7/8/9 ligands, could induce a strong secretion of IL-6 in supernatants in a dose dependent manner. The highest IL-6 secretions (between 500 and $1000 \mathrm{pg} / \mathrm{mL}$ ) were obtained with of TLR-1/2, 4, 6 ligands used at a high concentration, as expected. Double-stranded RNA ligands, engaging either TLR-3 or RIG-I/MDA-5, led to a lower, but yet significant level of IL-6 production (i.e. between 300 and $400 \mathrm{pg} / \mathrm{mL}$ ). Despite a good RNA expression induction, TLR-8 ligands did not lead to a strong accumulation of IL-6 in the supernatant (only around $30 \mathrm{pg} / \mathrm{mL}$ ). This could be due to 
fast turnover of the secreted cytokine after a very early expression of IL-6 at RNA level. In agreement with RNA expression data, TLR-7 and 9 ligands did not lead to any detectable level of IL-6. The same ligands that were able to induce IL-6 secretion could also increase the IP-10 production . However, TLR-3 and RIG-I/MDA5 ligands led to the higher production, with a respective secretion of around 2800 and $1400 \mathrm{pg} / \mathrm{mL}$ at the highest doses of ligands, as compared to the secretion of around $800 \mathrm{pg} / \mathrm{mL}$ with TLR-1/2 or 4 , and respectively 200 and $500 \mathrm{pg} / \mathrm{mL}$ with TLR-5 and 6 ligands. Similarly to what was obtained with IL-6 secretion, TLR-7, 8 and 9 did not lead to any detectable level of IP-10. Results obtained in $\mathrm{PHH}$ are shown in Figure 4B. In PHH even more IP-10, but less IL-6 (with the exception of TLR-4 agonisation) were produced as compared to dHepaRG.

In contrast, we could only detect biologically active type-I IFN, using a functional assay, in the supernatant of HepaRG cell stimulated only with very high (and rather cytotoxic in the context of multiple dosing; data not shown) doses of RIG-I and MDA/5 ligands (Sup.Fig. 3), thus suggesting that the interferon levels produced after stimulation by other prototypic ligands might be under the detection threshold of the assay.

\section{Exemplary comparison of expression and functionality of TLR-2 in dHepaRG} and $\mathrm{PHH}$

As a first attempt to compare the expression and functionality of all TLRs/RLRs in dHepaRg and PHH, we studied TLR-2 expression and function in both cell type using two additional batches of cells. Using Pam3CSK4 to stimulate and specific TLR-2 siRNA (siRNA against HCV was used as control) to control specificity, we have shown that i) the basal level of expression (RNA and protein) of this sensor is rather even in both cell types (Fig. 5A/5B; Sup.Fig. 2), ii) its expression can be strongly induced by Pam3CSK4 agonisation and decreased by specific siRNA (Fig. 
$5 \mathrm{~A} / 5 \mathrm{~B} / 5 \mathrm{C})$, and iii) its specific agonisation by ligands leads to a strong secretion of

326 IL-10 (slightly stronger in PHH as compared to dHepaRG) (Fig. 5D). Thus this pathway seems to be operational in hepatocytes.

\section{Antiviral activity of some TLR/RLR ligands in HBV-infected dHepaRG}

To fully characterize the functionality of the TLR/RLR receptors that are expressed in HepaRG cells, we have treated cells with TLR-1/2, 3, 4, 7, 8, 9 or RIG-I/MDA-5 ligands with non-toxic doses (as determined by $3 x$ exposure of HepaRG cells to ligands; Fig. 6D) for 24 hour before infecting them with HBV. A 24 hours inoculation with HBV was made in presence of cytokine produced during the $24 \mathrm{~h}$ exposure to ligands. Then, infected cells were washed and further retreated twice with the same dose of ligands respectively at days 1 and 4 post-infection. The impact of TLR/RLR ligands treatment on the establishment of HBV infection was analyzed at day 7 postinfection by measuring $\mathrm{HBV}$ viral protein secretion $(\mathrm{HBsAg} / \mathrm{HBeAg})$ and the accumulation of intracellular HBV DNA by qPCR. A strong antiviral activity was obtained with TLR-1/2 and TLR-4 ligands, as well as with a RIG-I/MDA-5 ligand (Fig. 6A/B/C), whereas weaker or no antiviral activity was observed with a TLR-3, 7 , and 8 ligands. Surprisingly, an antiviral activity was obtained with the TLR-9 ligand/agonist, which did not correlate with any production of IL-6 or IP-10. However the same antiviral activity was obtained with the control $\mathrm{CpG}$ ligand, thus suggesting that the phenotype obtained was independent of innate functions. 


\section{Discussion}

Hepatoma cell lines or transformed human hepatocytes are commonly used to study hepatotropic pathogens, however the relevance of these models is limited when studying the interplay between pathogens and hepatocyte innate immunity. Indeed pathogen sensing, IFN response and NF-KB signaling are commonly altered these cell types as compared to $\mathrm{PHH}$ [16]. RNA levels for TLR receptors and a set of downstream signaling molecules are lower in these cells compared to $\mathrm{PHH}$, and not modified in response to stimulation. Moreover, we previously showed that a type-I IFN response to HBV replication does not lead to an antiviral effect in transformed HepG2 cells while it suppressed viral replication in differentiated HepaRG cells [31]. Furthermore it has been observed that the patterns of cytokine secretion were also different even when a common transcription factor $(N F-\kappa B)$ was involved. The defects in TLR signaling observed in hepatoma cells was consistent with the hypothesis that innate immunity could play an important role in suppressing tumorigenesis [16]. These defects make them of limited interest to study innate immune response induced by an hepatotropic pathogen [14, 15].

In contrast, $\mathrm{PHH}$ and HepaRG cells, which are mainly non-cancerous, functional for IFN signaling, and permissive to HBV replication, are more relevant models [20, 21]. Their transcriptomes have been shown to be closer to each other, as compared to hepatoma cells, and closer to that of liver biopsies [32]. The relatively low replication rate of hepatotropic viruses (low rate for HBV and virtually no permissivity to $\mathrm{HCV}$ ) in HepaRG cells might result, at least in part, from a cellular antiviral response [33]. Indeed, an experimentally strong HBV expression and replication after baculoviral delivery of HBV was shown to induce a potent anti-HBV IFN response, while in the same experimental conditions this IFN response did not show any antiviral effect in transformed HepG2 cells [31]. Therefore HepaRG cells, because 
physiologically related to $\mathrm{PHH}[34]$, were expected to be a valuable tool to study

373 host/pathogen interactions. However, detailed features of this immune response

374 were still unclear and the present study provides the first characterization and functionality of PRRs gene expression in an HBV susceptible and non-cancerous cell line, the HepaRG cell in comparison with $\mathrm{PHH}$.

In this respect, our study showed that RNA of all TLR as well as cytoplasmic helicases RIG-I and MDA5 receptors, could be detected in either proliferative or differentiated HepaRG cells, in similar amount than in $\mathrm{PHH}$. While all RNA could be detected, the level of expression of $t / r-7,8,9$ and $t / r-10$ proved to be very low in hepatocytes. Protein expression analysis showed that all TLR were expressed in both dHepaRG and $\mathrm{PHH}$, with slightly higher levels of expression in HepaRG. The detection of TLR-7, 8, and 9 at protein level contrasted with the low RNA expression, and suggests that post-transcriptional mechanisms could be involved to allow detectable protein expression. RIGI and MDA5 were also expressed at the protein level and highly inducible after interferon stimulation. For most PRR, the stimulation by their prototypic ligands could induce their own expression by positive feed-back. These stimulations could also lead to the RNA induction of several cytokines such as IL-6, with the exception of TLR-7 and 9. However, TLR-7 and 9 ligands could somehow induce a weak IFN- $\alpha$ and $\beta$ RNA expression implying that all these TLR could be slightly functional, yet not leading to detectable secretion of IL-6 or IP-10. In humans, the expression of TLR-7 and TLR9- is mainly confined to plasmacytoid dendritic cells and B-lymphocytes. However, low levels of TLR7 and or TLR9 have been reported in other cell types, including hepatocytes [35] particularly in the setting of chronic inflammation [36]. In addition, the functionality of TLR-3 and RIG-I/MDA-5 pathway was demonstrated after cell stimulation with extracellular dsRNA (poly $(\mathrm{I}: \mathrm{C})$ ) and cytoplasmic dsRNA (poly(l:C)-lyovec) respectively showing an induction of IFNa, $\beta$ and $\lambda$ as well as ISGs (such as ISG56). More importantly, after stimulation 
with prototypic ligands targeting PRR, using different doses of ligands, IL-6 could be secreted and detected at high levels up to $1000 \mathrm{pg} / \mathrm{ml}$ with TLR-1/2, 4, and 6 stimulations, and between 100 and $500 \mathrm{pg} / \mathrm{mL}$ for TLR-3, 5, as well as RLR stimulations. A weak IL-6 expression was obtained with TLR-8 stimulation, but no secretion could be evidenced for TLR-9 and TLR-7 ligands. In contrast, dsRNA ligands engaging either TLR-3 or RIG-I/MDA-5 were more prone to induce secretion of IP-10 (i.e. with production of 2800 and $1400 \mathrm{pg} / \mathrm{mL}$ respectively), an IFN-related chemokine. Other functional PRR, based on their ability to induce IL-6 secretion, were also capable to induce IP-10. Interestingly, type-I interferon could only be detected in cell supernatants after stimulation with high, yet rather toxic doses of RIG-I and MDA-5 ligands, thus suggesting that it is difficult to measure the production of type-I IFN by hepatocytes.

An important part of the demonstration of PRR functionality in HepaRG relies on the antiviral effect observed with some ligands regarding the establishment of HBV infection in these HepaRG cells. Indeed, while it was shown that IL-6 could have an antiviral effect against HBV [37], many other cytokine may also have antiviral effect. Therefore, the engagement of PRR in HepaRG was expected to lead to conditioned media having potent antiviral activity. This was strongly obtained with TLR-1/2 and 4 agonists, as well as with RIG-I/MDA-5 ligands, but surprisingly less with a TLR-3 ligand, despite its ability to better induce the production of IL-6 and IP-10 as compared to a RIG-I/MDA5 agonist. This result could only be explained by the ability of RIG-I/MDA-5 agonists to induce measurable amount of type-I IFNs compared to TLR-3 agonists. The strongest antiviral activity was obtained by Pam3CSK4 agonisation of TLR-1/2, a pathway which is well functional in hepatocytes, as shown by more advanced comparison done in both dHepaRG and PHH (Fig. 5). These interesting results warrant further investigation on this pathway and its antiviral effectors. 
Infections by hepatotropic pathogens can be cleared once innate immune

activation and pathogen-specific $\mathrm{T}$ cell responses predominate over pathogen immune escape mechanisms, as it occurs in HAV infections, and in cases of resolution of acute HBV or HCV infections. Viral persistence in hepatocytes can occur by escaping both innate and adaptive immune responses, as observed in chronic HBV or HCV infections. HepaRG exhibits functional TLR and dsRNAactivated signaling pathways in contrast to cultured hepatoma cells [38]. It appears unclear why hepatoma cell lines are unresponsive to a wide range of TLR agonists, but RNA levels for TLR receptor and a set of downstream signaling molecules appear to be lower in hepatoma cell lines than in primary hepatocytes [16]. However, low responsiveness to ligands was observed even when the cognate TLR was expressed at apparently normal levels, suggesting that other downstream factors must be involved. Our data show that HepaRG cells express functional PRRs. The activation of these PRRs leads to the production of cytokines/chemokines, including cytokines bearing antiviral activity. This study opens doors to relevant and detailed analyses of hepatocyte-like cell response to hepatotropic viruses or other hepatotropic pathogens in the absence of non-parenchymal or liver resident immune cells. Therefore, the HepaRG cell line that maintains the functional properties of primary human hepatocytes provides a unique tool for the understanding of the interplay between the innate immune response and hepatotropic pathogens. This work may have potential applications to study the activation of hepatocyte innate immunity by these pathogens, the evasion to innate immunity by these pathogens, and mechanism by which innate responses could be restored. 
451 [1] Protzer U, Maini MK, Knolle PA. Living in the liver: hepatic infections. Nat Rev Immunol 2012;12:201-213.

453 [2] El-Serag HB. Epidemiology of viral hepatitis and hepatocellular carcinoma. Gastroenterology 2012;142:1264-1273 e1261.

455 [3] Guidotti LG, Chisari FV. Immunobiology and pathogenesis of viral hepatitis. Annu Rev Pathol 2006;1:23-61.

457 [4] Takeuchi O, Akira S. Pattern recognition receptors and inflammation. Cell 2010;140:805-820.

458 [5] Wu J, Chen ZJ. Innate immune sensing and signaling of cytosolic nucleic acids. Annual review of immunology 2014;32:461-488.

460 [6] Akira S, Uematsu S, Takeuchi O. Pathogen recognition and innate immunity. Cell 2006;124:783-801.

462 [7] Kawai T, Akira S. The role of pattern-recognition receptors in innate immunity: update on Toll-like receptors. Nat Immunol 2010;11:373-384.

464 [8] Bowie AG, Haga IR. The role of Toll-like receptors in the host response to viruses. Mol Immunol 2005;42:859-867.

[9] Ait-Goughoulte M, Lucifora J, Zoulim F, Durantel D. Innate antiviral immune responses to hepatitis B virus. Viruses 2010;2:1394-1410.

[10] Heim MH. Innate immunity and HCV.J Hepatol 2013;58:564-574.

[11] Bertoletti A, Ferrari C. Innate and adaptive immune responses in chronic hepatitis B virus infections: towards restoration of immune control of viral infection. Gut 2012;61:1754-1764.

[12] Nishimura M, Naito $S$. Tissue-specific mRNA expression profiles of human toll-like receptors and related genes. Biol Pharm Bull 2005;28:886-892.

[13] Liu S, Gallo DJ, Green AM, Williams DL, Gong X, Shapiro RA, et al. Role of toll-like receptors in changes in gene expression and NF-kappa B activation in mouse hepatocytes stimulated with lipopolysaccharide. Infect Immun 2002;70:3433-3442.

[14] Melen K, Keskinen P, Lehtonen A, Julkunen I. Interferon-induced gene expression and signaling in human hepatoma cell lines. J Hepatol 2000;33:764-772.

[15] Keskinen P, Nyqvist M, Sareneva T, Pirhonen J, Melen K, Julkunen I. Impaired antiviral response in human hepatoma cells. Virology 1999;263:364-375.

[16] Alexopoulos LG, Saez-Rodriguez J, Cosgrove BD, Lauffenburger DA, Sorger PK. Networks inferred from biochemical data reveal profound differences in toll-like receptor and inflammatory signaling between normal and transformed hepatocytes. Mol Cell Proteomics 2010;9:1849-1865.

[17] Ni Y, Lempp FA, Mehrle S, Nkongolo S, Kaufman C, Falth M, et al. Hepatitis B and D viruses exploit sodium taurocholate co-transporting polypeptide for species-specific entry into hepatocytes. Gastroenterology 2014;146:1070-1083.

[18] Shlomai A, Schwartz RE, Ramanan V, Bhatta A, de Jong YP, Bhatia SN, et al. Modeling host interactions with hepatitis $B$ virus using primary and induced pluripotent stem cell-derived hepatocellular systems. Proceedings of the National Academy of Sciences 2014;111:12193-12198.

[19] Parent R, Marion MJ, Furio L, Trepo C, Petit MA. Origin and characterization of a human bipotent liver progenitor cell line. Gastroenterology 2004;126:1147-1156. hepatoma cell line by hepatitis B virus. Proc Natl Acad Sci U S A 2002;99:15655-15660. 
[21] Gripon P, Diot C, Theze N, Fourel I, Loreal O, Brechot C, et al. Hepatitis B virus infection of adult human hepatocytes cultured in the presence of dimethyl sulfoxide. Journal of virology 1988;62:4136-4143.

[22] Estornes $Y$, Toscano F, Virard F, Jacquemin G, Pierrot A, Vanbervliet B, et al. dsRNA induces apoptosis through an atypical death complex associating TLR3 to caspase-8. Cell Death Differ 2012;19:1482-1494.

[23] Khvalevsky E, Rivkin L, Rachmilewitz J, Galun E, Giladi H. TLR3 signaling in a hepatoma cell line is skewed towards apoptosis. J Cell Biochem 2007;100:1301-1312.

[24] Troadec MB, Glaise D, Lamirault G, Le Cunff M, Guerin E, Le Meur N, et al. Hepatocyte iron loading capacity is associated with differentiation and repression of motility in the HepaRG cell line. Genomics 2006;87:93-103.

[25] Maire M, Parent R, Morand AL, Alotte C, Trepo C, Durantel D, et al. Characterization of the double-stranded RNA responses in human liver progenitor cells. Biochem Biophys Res Commun 2008;368:556-562.

[26] Lecluyse EL, Alexandre E. Isolation and culture of primary hepatocytes from resected human liver tissue. Methods Mol Biol 2010;640:57-82.

[27] Hantz O, Parent R, Durantel D, Gripon P, Guguen-Guillouzo C, Zoulim F. Persistence of the hepatitis B virus covalently closed circular DNA in HepaRG human hepatocyte-like cells. The Journal of general virology 2009;90:127-135.

[28] Sainz B, Jr., Chisari FV. Production of infectious hepatitis C virus by well-differentiated, growth-arrested human hepatoma-derived cells. Journal of virology 2006;80:10253-10257.

[29] Jammart B, Michelet M, Pecheur El, Parent R, Bartosch B, Zoulim F, et al. Very-low-density lipoprotein (VLDL)-producing and hepatitis C virus-replicating HepG2 cells secrete no more lipoviroparticles than VLDL-deficient Huh7.5 cells. Journal of virology 2013;87:5065-5080.

[30] Ank N, Iversen MB, Bartholdy C, Staeheli P, Hartmann R, Jensen UB, et al. An important role for type III interferon (IFN-lambda/IL-28) in TLR-induced antiviral activity. J Immunol 2008;180:24742485.

[31] Lucifora J, Durantel D, Testoni B, Hantz O, Levrero M, Zoulim F. Control of hepatitis B virus replication by innate response of HepaRG cells. Hepatology 2010;51:63-72.

[32] Hart SN, Li Y, Nakamoto K, Subileau E-a, Steen D, Zhong X-b. A Comparison of Whole Genome Gene Expression Profiles of HepaRG Cells and HepG2 Cells to Primary Human Hepatocytes and Human Liver Tissues. Drug Metabolism and Disposition 2010;38:988-994.

[33] Marion MJ, Hantz O, Durantel D. The HepaRG cell line: biological properties and relevance as a tool for cell biology, drug metabolism, and virology studies. Methods Mol Biol 2010;640:261-272.

[34] Guguen-Guillouzo C, Guillouzo A. General review on in vitro hepatocyte models and their applications. Methods Mol Biol 2010;640:1-40.

[35] Lee J, Wu CC, Lee KJ, Chuang TH, Katakura K, Liu YT, et al. Activation of anti-hepatitis C virus responses via Toll-like receptor 7. Proc Natl Acad Sci U S A 2006;103:1828-1833.

[36] Takii $Y$, Nakamura $M$, Ito $M$, Yokoyama T, Komori A, Shimizu-Yoshida $Y$, et al. Enhanced expression of type I interferon and toll-like receptor-3 in primary biliary cirrhosis. Lab Invest 2005;85:908-920.

[37] Hosel M, Quasdorff $M$, Wiegmann K, Webb D, Zedler $U$, Broxtermann $M$, et al. Not interferon, but interleukin- 6 controls early gene expression in hepatitis B virus infection. Hepatology 2009;50:1773-1782.

[38] Lanford RE, Guerra B, Lee H, Averett DR, Pfeiffer B, Chavez D, et al. Antiviral effect and virushost interactions in response to alpha interferon, gamma interferon, poly(i)-poly(c), tumor necrosis 
539 factor alpha, and ribavirin in hepatitis C virus subgenomic replicons. Journal of virology $540 \quad 2003 ; 77: 1092-1104$.

541 
543

544

\begin{tabular}{|c|c|c|}
\hline Gene & Forward primer sequence $\left(5^{\prime}-3^{\prime}\right)$ & Reverse primer sequence $\left(5^{\prime}-3^{\prime}\right)$ \\
\hline TLR1 & caggccctcttcctcgttaga & ttcctaaaggtagaagctgttcttca \\
\hline TLR2 & ctctcggtgtcggaat & cccgctcactgtaagaa \\
\hline TLR3 & tttgcgaagaggaatgtttaaatct & cacctatccgttctttctgaactg \\
\hline TLR4 & tcttggtggaagttgaacg & gccacaccgggaataa \\
\hline TLR5 & gtaccctgactcgttct & ttctgcacccatgtga \\
\hline TLR6 & agtggacccagactcg & agttcgtaatggcacc \\
\hline TLR8 & tgagctgcgctaccac & cttctgccttcgggtt \\
\hline TLR9 & ggcccccggcttctt & caggagtggtccactgtcttga \\
\hline TLR10 & gcattcccaccaggtatcataaac & aaagcccacatttacgcctatc \\
\hline RIGI & gctgatgaaggcattgacattg & cagcattactagtcagaaggaagca \\
\hline MDA5 & cccatgacacagaatgaacaaaa & cgagaccataacggataacaatgt \\
\hline IFN $\alpha$ & gtgaggaaatacttccaaagaatcac & tctcatgatttctgctctgacaa \\
\hline IFN $\beta$ & gccgcattgaccatgtatgaga & gagatcttcagtttcggaggtaac \\
\hline IL28b & taagagggccaaagatgcctt & ctggtccaagacatccccc \\
\hline IL29 & gtgactttggtgctaggcttg & gcctcaggtcccaattccc \\
\hline IL6 & acccctgacccaaccacaaat & agctgcgcagaatgagatgagtt \\
\hline ISG56 & agccaacatgtcctcacagac & cttctaccactgtttcatgc \\
\hline$\beta$-actin & tggcattgccgacaggatgc & tctgctggaggtggacagcga \\
\hline RPLPO & caccattgaaatcctgagtgatgt & tgaccagcccaaaggagaag \\
\hline
\end{tabular}

545

546

547

548

549

550

551

552

553

554 
556

557

558

559

560

561

562

563

564

565

566

567

568

569

570

571

572

573

574

575

576

577

578

579

580

Fig. 1. mRNA expression of TLR and $R L R$ in differentiated and proliferative HepaRG. A and B) RT-qPCR analysis of TLR/RLR expression in dHepaRG, PHH, HepG2, and Huh7. The relative RNA expression was normalized to housekeeping genes rplpo (panel A) or $\beta$-actin cDNA $\left(2^{-\Delta C t}\right)$ (panel B). C) Comparative RNA expression of TLR/RLR in pHepaRG and dHepaRG cells. RT-qPCR analysis of TLR/RLR expression was normalized to housekeeping genes ( $r p / p 0$ and $b$-actin) and relatively compared to pHepaRG cells. Results are given as a mean \pm SEM of 3 (or 4 for $\mathrm{PHH} ; \mathrm{n} \geq 3$ ) independent experiments (with biological triplicate) with 3 batches of $\mathrm{PHH}$ from different donors.

Fig. 2. Protein expression of PRR in pHepaRG and dHepaRG cells. A and B) TLR expression analyzed by FACS. Black histograms represent staining with the indicated TLR antibody, shaded gray histograms represent the isotype control, in pHepaRG, dHepaRG and PHH. C) Western-Blot analysis of RIGI and MDA5 in dHepaRG (and PHH), with or without IFNa (1000 UI/mL) induction. D) Expression of some TLRs in hepatocyte-like cells as compared to cholangiocyte-like cells measured by FACS, and reported on graph as fold increase of MFI (using cholangiocyte as reference, set at 1$)$.

Fig. 3. Induction of PRR, cytokine, and ISG gene expression in dHepaRG cells \& secretion of IL-6 and IP-10 after stimulation with prototypic ligands. A) Gene expression was analyzed $(n=3)$ following $2 h, 4 h$, 8 h or $16 \mathrm{~h}$ stimulation with prototypic ligands of TLR1/2 (Pam3CSK4, 500 ng/mL), TLR3 (Poly(I:C)-LMW, $10 \mu \mathrm{g} / \mathrm{mL})$ TLR4 (LPS, $1 \mu \mathrm{g} / \mathrm{mL}$ ), TLR5 (FLA-BS, $10 \mu \mathrm{g} / \mathrm{mL}$ ) TLR6 (FSL1, $5 \mu \mathrm{g} / \mathrm{mL}$ ), TLR7 (Imiquimod, $10 \mu \mathrm{g} / \mathrm{mL}$ ) TLR8 (ssRNA40, $10 \mu \mathrm{g} / \mathrm{mL})$, TLR9 (CpG-2395, $5 \mu \mathrm{M})$ RIGI/MDA5 (Poly(I:C)-LMW-lyovec, $1 \mu \mathrm{g} / \mathrm{mL}$ ). After stimulation RT-qPCR were performed on targeted prr (self activation by cognate ligands; PRR are indicated on the x-axis), il-6, 
581

582

ifn- $\beta$, ifn- $\alpha$, il-28B, il-29 and isg56 genes. The RNA level expression was normalized to housekeeping genes and relatively compared to the non-stimulated control. B and C) The secretion of IL-6 and IP-10, after 24 hours of stimulation with different doses of indicated ligands, was quantified by ELISA. The concentration used for the ligands were: TLR-1/2 (Pam3CSK4, 500-50-5 ng/mL), TLR-3 (Poly(I:C)-LMW, 10-1-0.1 $\mu \mathrm{g} / \mathrm{mL}$ ), TLR-4 (LPS, 1-0.1-0.01 $\mu \mathrm{g} / \mathrm{mL}$ ), TLR-5 (Flagellin, 10-1-0.1 $\mu \mathrm{g} / \mathrm{mL}$ ), TLR-6 (FSL1, 5-1-0.2 $\mu \mathrm{g} / \mathrm{mL}$ ), TLR-7 (Imiquimod, 10-1-0.1 $\mu \mathrm{g} / \mathrm{mL}$ ), TLR-8 (ssRNA40, 10-2$0.4 \mu \mathrm{g} / \mathrm{mL}$ ), TLR9 (CpG, 5-1-0.2 $\mu \mathrm{M}$ ) RIGI/MDA5 (Poly(I:C)-LMH-Lyovec, 1-0.2-0.04 $\mu \mathrm{g} / \mathrm{mL}$ ). Cut-offs for IL-6 and IP-10 ELISA assays are $2.5 \mathrm{pg} / \mathrm{mL}$; there are materialized on panels $\mathrm{B}$ and $\mathrm{C}$ by dotted lines.

Fig. 4. Induction of IL-6 and IFNs gene expression in PHH cells \& secretion of IL-6 and IP-10 after stimulation with prototypic ligands. A) Gene expression was analyzed $(n=3)$ after $16 \mathrm{~h}$ of stimulation with prototypic ligands of TLR1/2 (Pam3CSK4, 500 ng/mL), TLR3 (Poly(l:C)-LMW, $10 \mu \mathrm{g} / \mathrm{mL}$ ) TLR4 (LPS, $1 \mu \mathrm{g} / \mathrm{mL}$ ), TLR5 (FLA-BS, $10 \mu \mathrm{g} / \mathrm{mL}$ ) TLR6 (FSL1, $5 \mu \mathrm{g} / \mathrm{mL}$ ), TLR7 (Imiquimod, $10 \mu \mathrm{g} / \mathrm{mL}$ ) TLR8 (ssRNA40, $10 \mu \mathrm{g} / \mathrm{mL}$ ), TLR9 (CpG-2395, $5 \mu \mathrm{M}$ ) RIGI/MDA5 (Poly(l:C)-LMWlyovec, $1 \mu \mathrm{g} / \mathrm{mL}$ ). After stimulation RT-qPCR were performed on il- 6 , ifn- $\beta$, ifn- $\alpha$, il$28 B$, and il-29 genes. The RNA level expression was normalized to housekeeping genes and relatively compared to the non-stimulated control. B) Secretion of IL-6 and IP-10, after 24 hours of stimulation with a single dose of indicated ligands, was quantified by ELISA. The concentration used for the ligands were: TLR-1/2 (Pam3CSK4, 500 ng/mL), TLR-3 (Poly(l:C)-LMW, $10 \mu \mathrm{g} / \mathrm{mL}$ ), TLR-4 (LPS, $1 \mu \mathrm{g} / \mathrm{mL}$ ), TLR-5 (Flagellin, $10 \mu \mathrm{g} / \mathrm{mL}$ ), TLR-6 (FSL1, $5 \mu \mathrm{g} / \mathrm{mL}$ ), TLR-7 (Imiquimod, $10 \mu \mathrm{g} / \mathrm{mL}$ ), TLR-8 (ssRNA40, $10 \mu \mathrm{g} / \mathrm{mL}$ ), TLR9 (CpG, $5 \mu \mathrm{M}$ ) RIGI/MDA5 (Poly(l:C)-LMH-Lyovec, $1 \mu \mathrm{g} / \mathrm{mL}$ ). Cut-offs for IL-6 and IP-10 ELISA assays are $2.5 \mathrm{pg} / \mathrm{mL}$. 
607

608

609

610

611

612

613

614

615

616

$\mathrm{dHepaRG}$ and $\mathrm{PHH}$ were either not or transfected with either siRNA against TLR2 or control siRNA (i.e. targeting $\mathrm{HCV}$ ) for $24 \mathrm{~h}$, then treated or not for $24 \mathrm{~h}$ with Pam3CSK4 (500 ng/mL). Then RNAs were extracted and subjected to RTqPCR with TLR-2 specific primers. A plasmid containing TLR-2 gene was use to calculate copies/ $\mu \mathrm{L}$. B and C) Protein were extracted and subjected to WB analysis with an anti-TLR2 and an anti-actin to control loading. D) ELISA was performed on supernatant for the detection of IP-10. Results for (A and D) are given as a mean \pm SEM of 2 independent experiments $(n=2$, but with biological quadruplicate for each experiment) and differences were considered as statistically significant to the control condition when $\mathrm{p}$ value was $\leq 0.05\left(^{*}\right)$.

Fig. 6. Effect of stimulation of some PRR receptors by ligands on HBV infection establishment. Secreted $\mathrm{HBsAg}(\mathrm{A}), \mathrm{HBeAg}(\mathrm{B})$, and intracellular HBV DNA accumulation (C) were measured at day 7 post-infection by ELISA and qPCR in HBV-infected dHepaRG cells, which were pre-treated (24h prior HBV inoculation), then twice treated post-infection (day 1 and 4 post-infection) with indicated ligands. Toxicity (D) was evaluated in the same conditions by the neutral red assay. The concentration used were: $500 \mathrm{ng} / \mathrm{mL}$ of Pam3C4 (TLR-1/2), $10 \mu \mathrm{g} / \mathrm{mL}$ of poly(l:C)LMH (TLR-3), $500 \mathrm{ng} / \mathrm{mL}$ of LPS (TLR-4), $5 \mu \mathrm{g} / \mathrm{mL}$ of CL264 (TLR-7), $10 \mu \mathrm{g} / \mathrm{mL}$ of R848 (TLR-7/8), $5 \mu \mathrm{M}$ of CpG-2395 (TLR-9), $5 \mu \mathrm{M}$ of CpG-2395 control, $0.01 \mu \mathrm{g} / \mathrm{mL}$ of poly(I:C)-LMW-lyovec (RIG-I/MDA-5). Results are given as a mean \pm SEM of 3 independent experiments (each with biological triplicate) and differences were considered as statistically significant to the control condition when $p$ value was $\leq 0.05$ ${ }^{*}$ ). Cut-offs for HBeAg and HBsAg ELISA assays are respectively $1 \mathrm{NCU} / \mathrm{mL}$ and 2.5 $\mathrm{ng} / \mathrm{mL}$; there are materialized on panels $A$ and $B$ by dotted lines. 
Figure 1

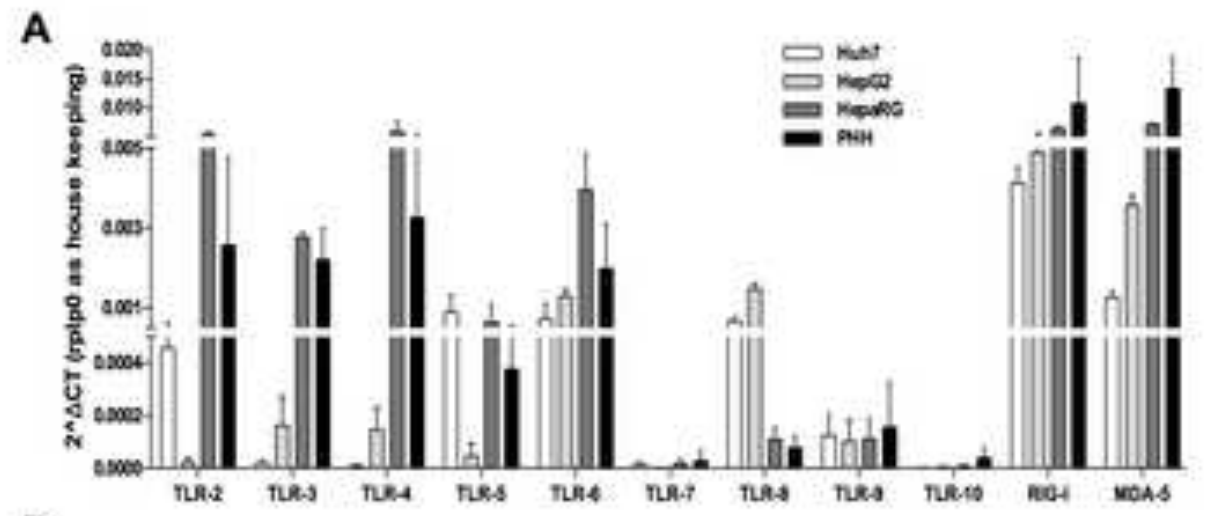

B

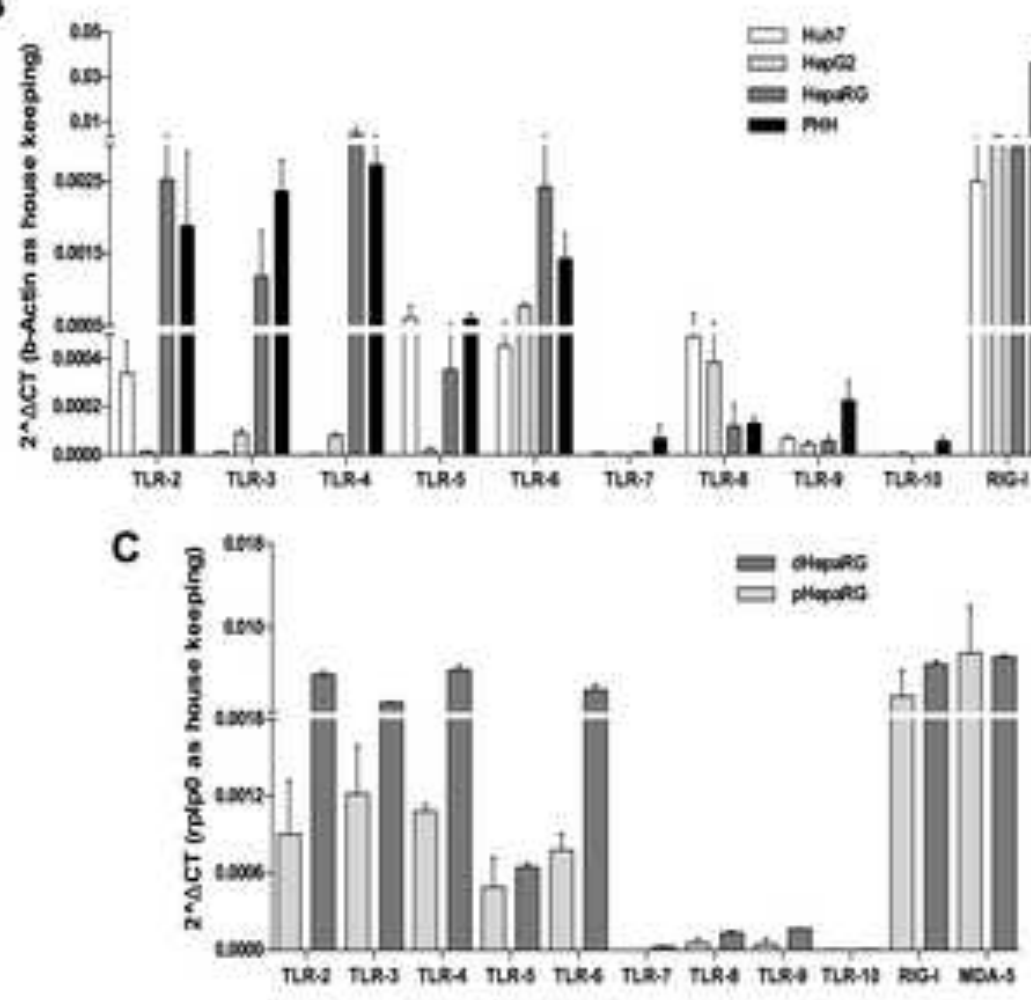




\section{Figure 2}
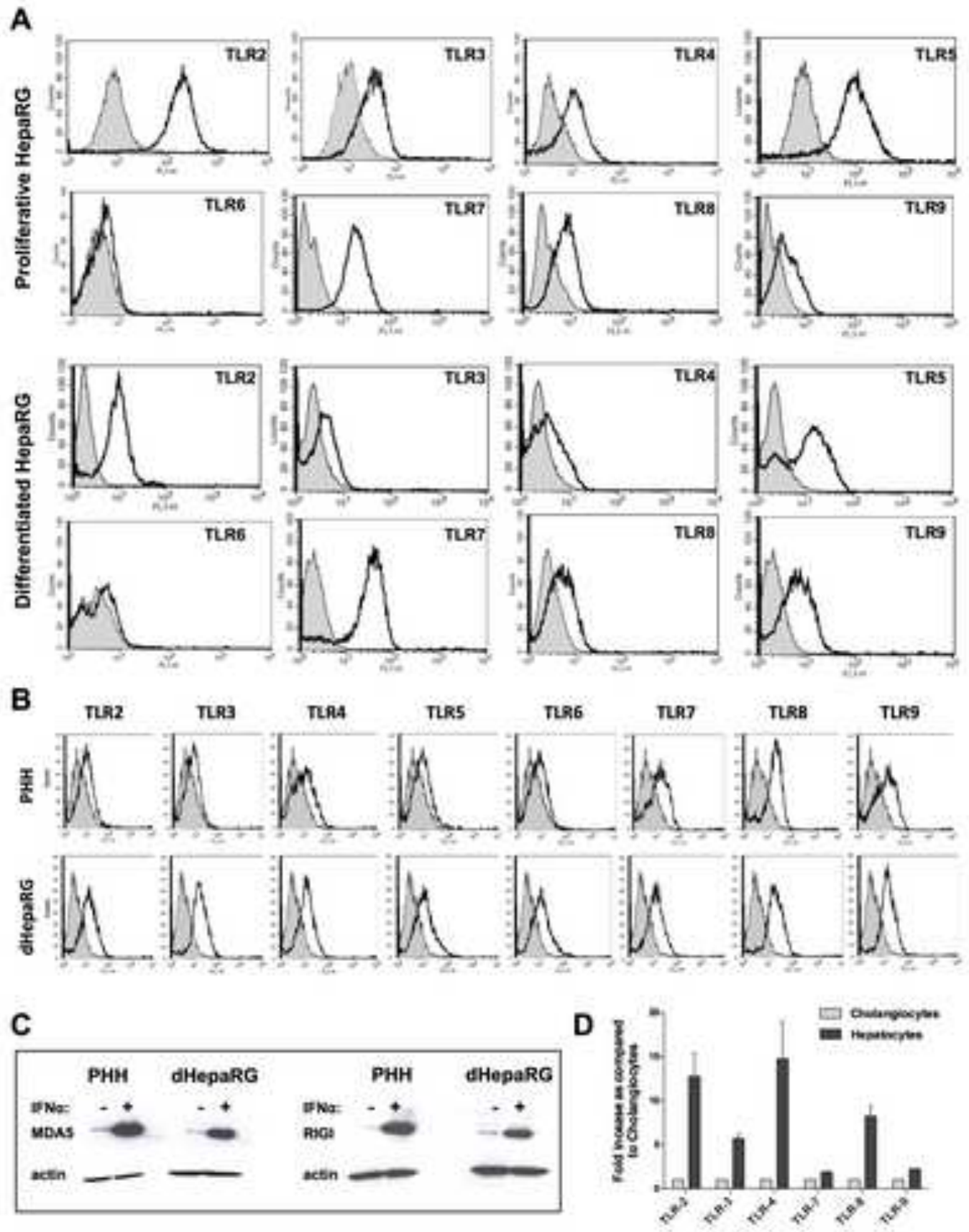
Figure 3
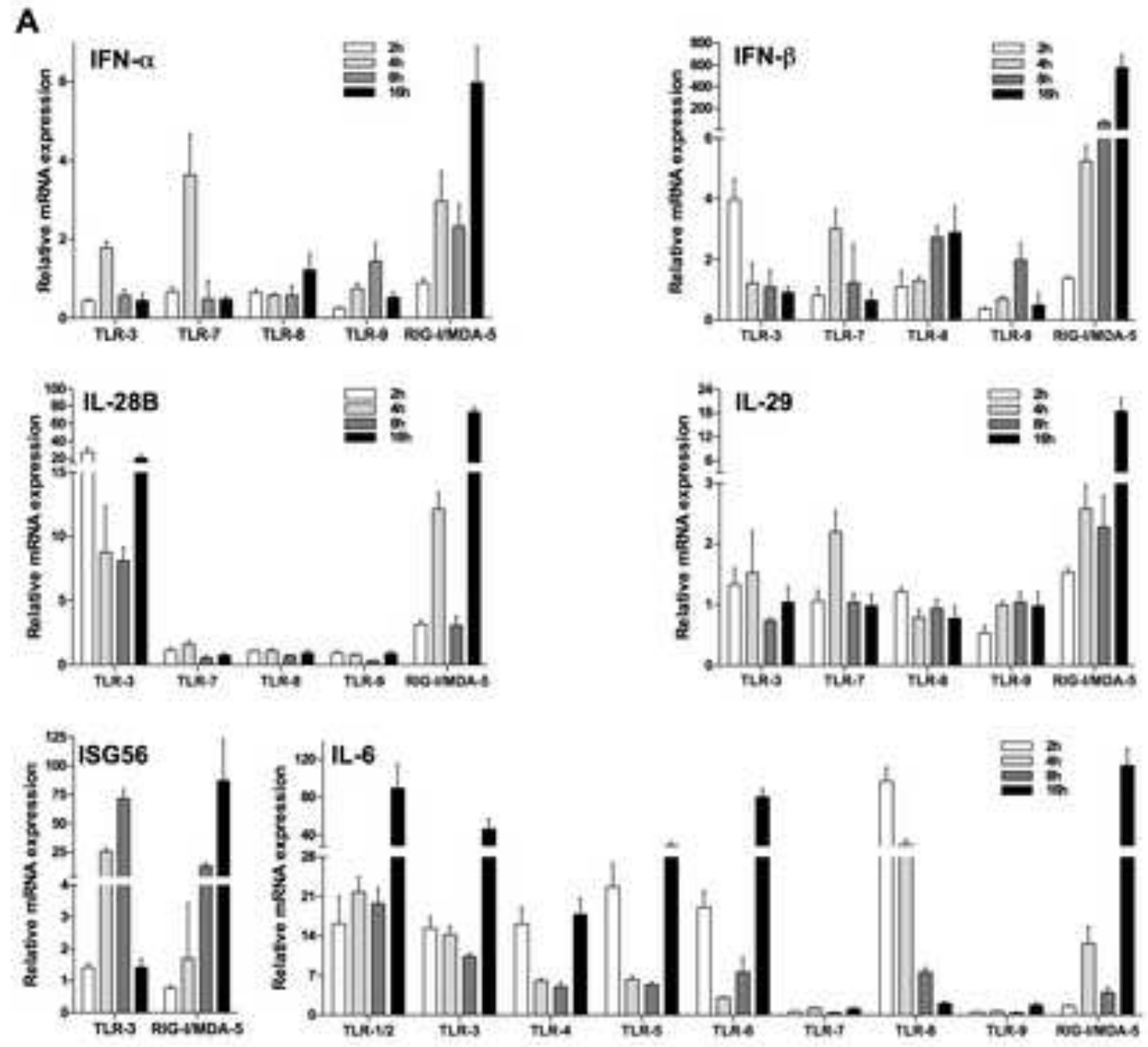
Figure 3
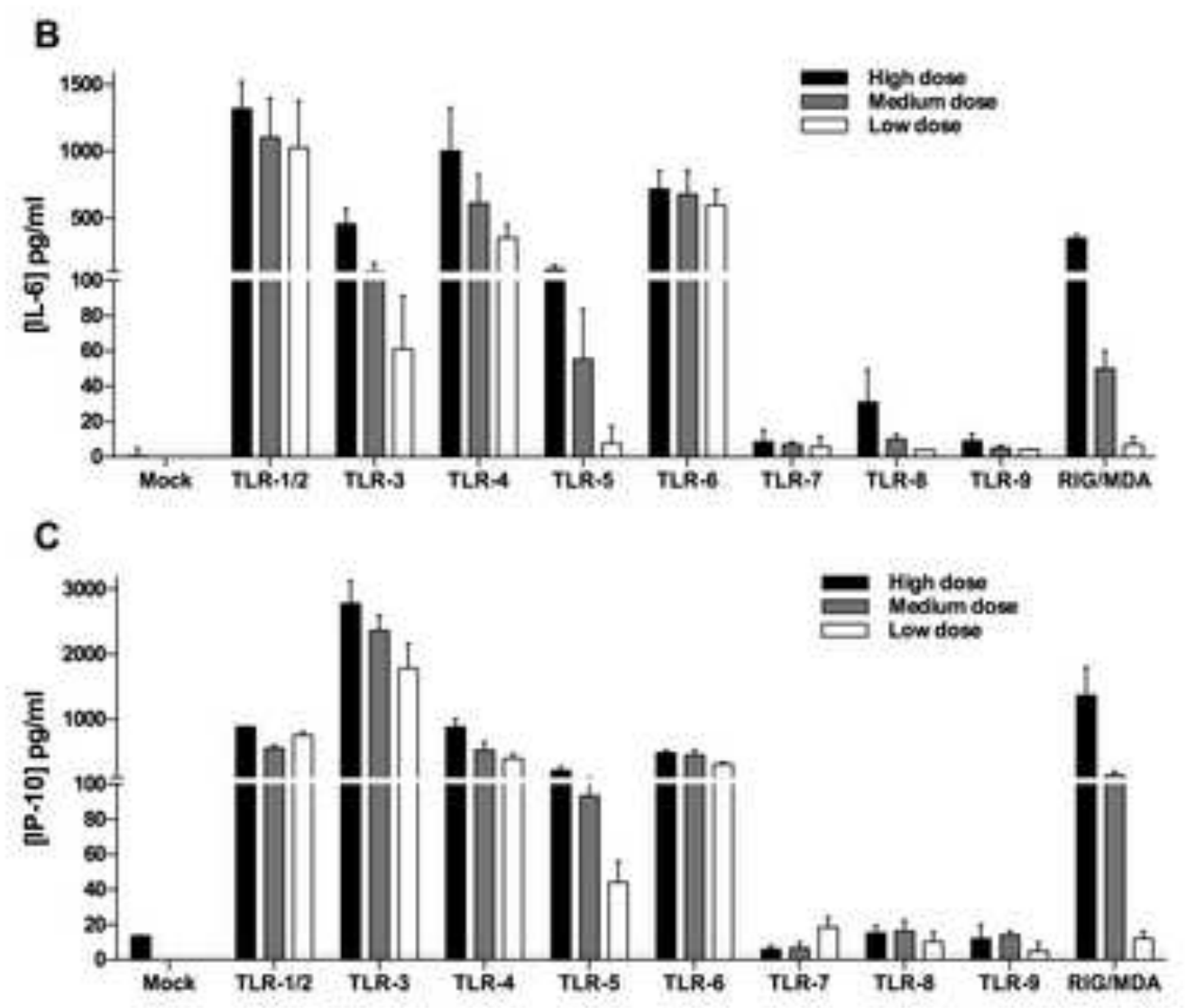


\section{Figure 4}

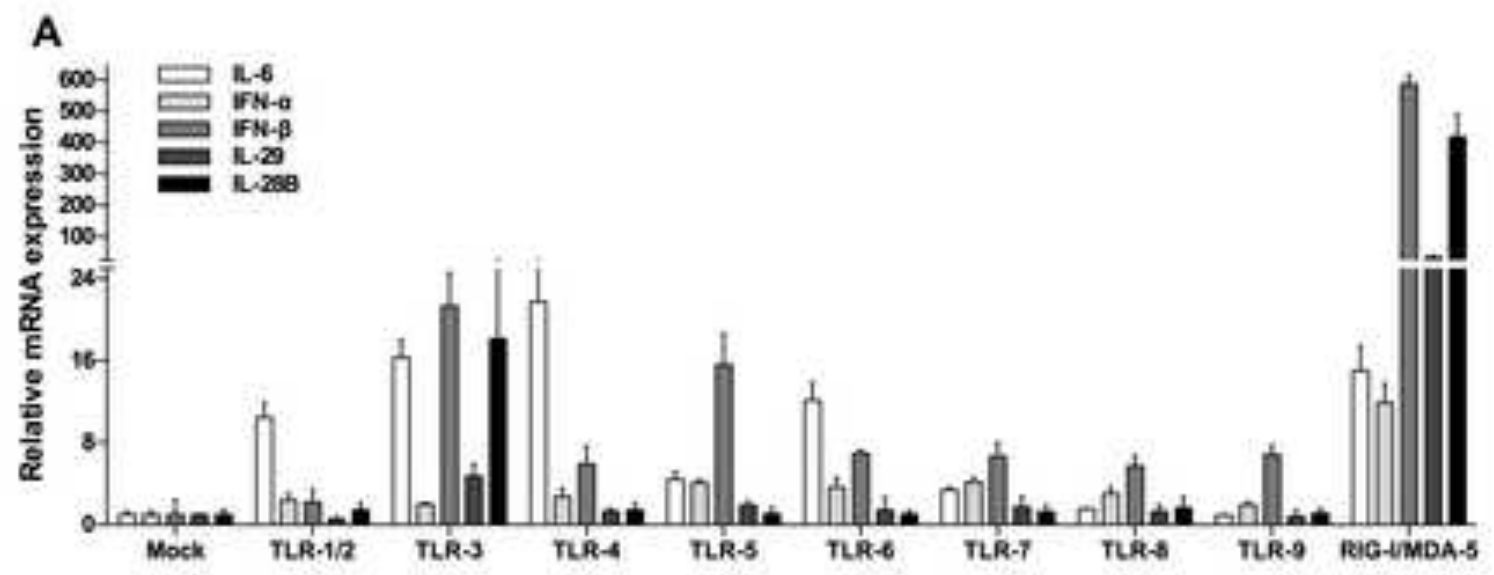

B

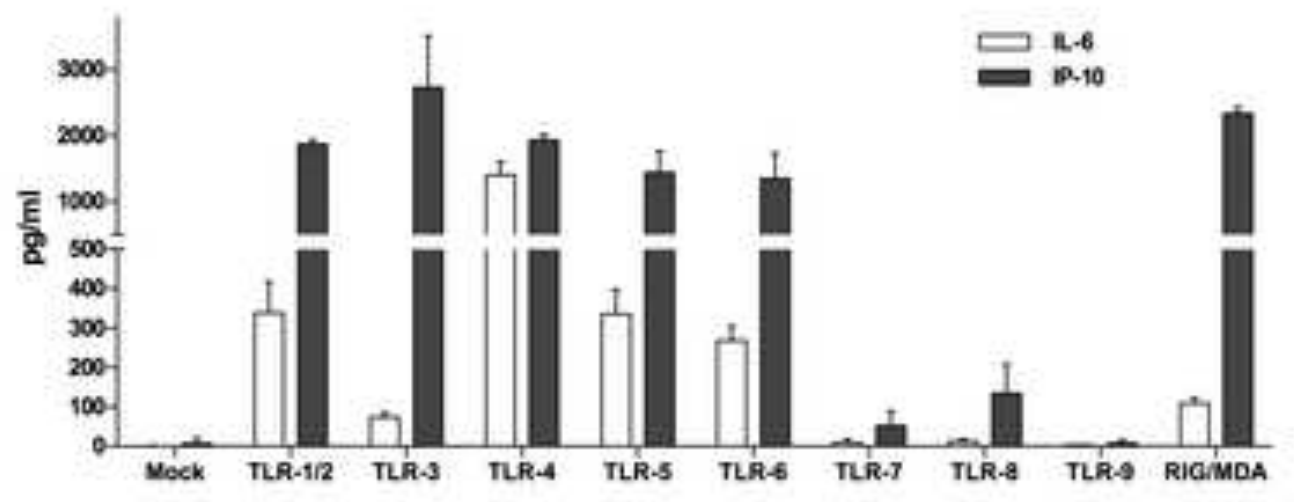




\section{Figure 5}

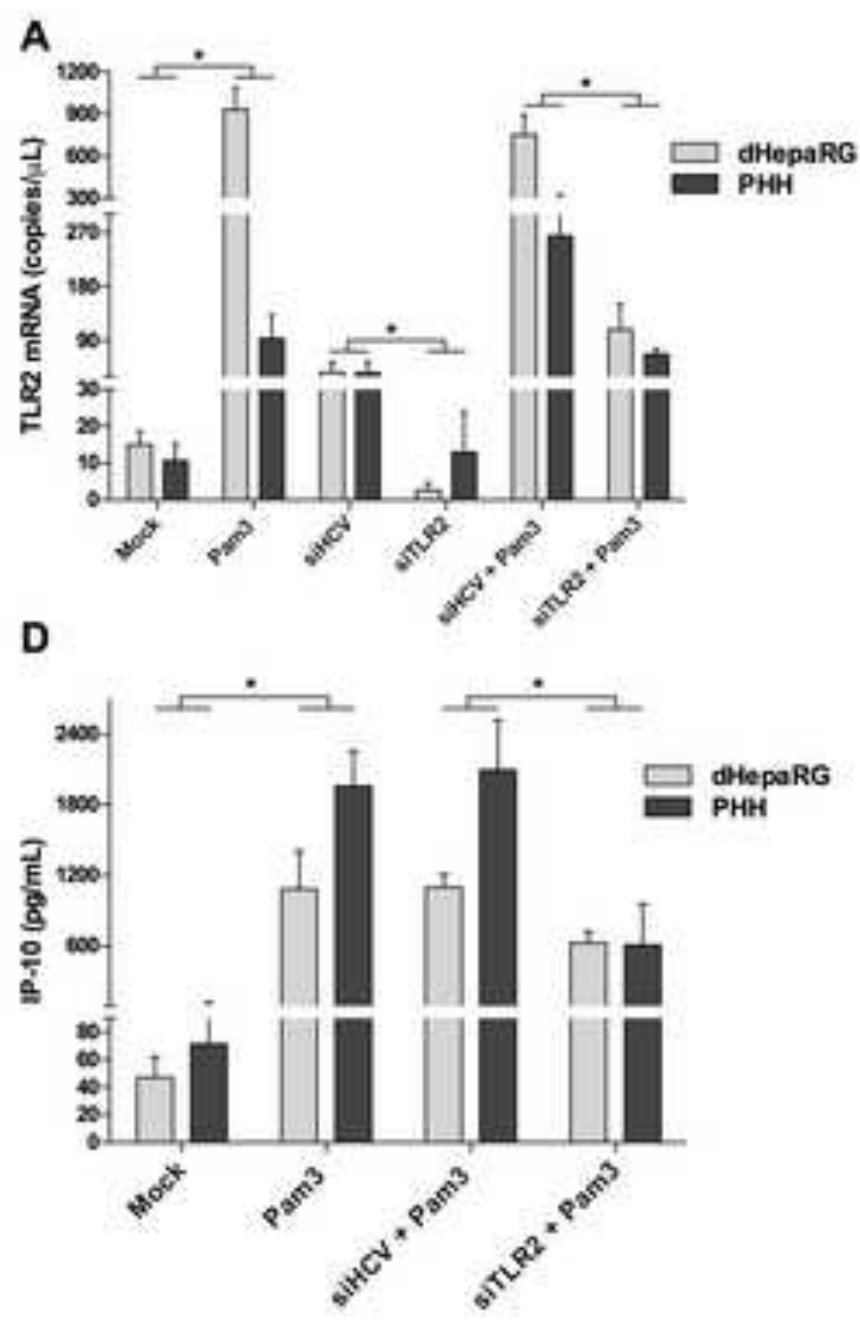

\section{B}
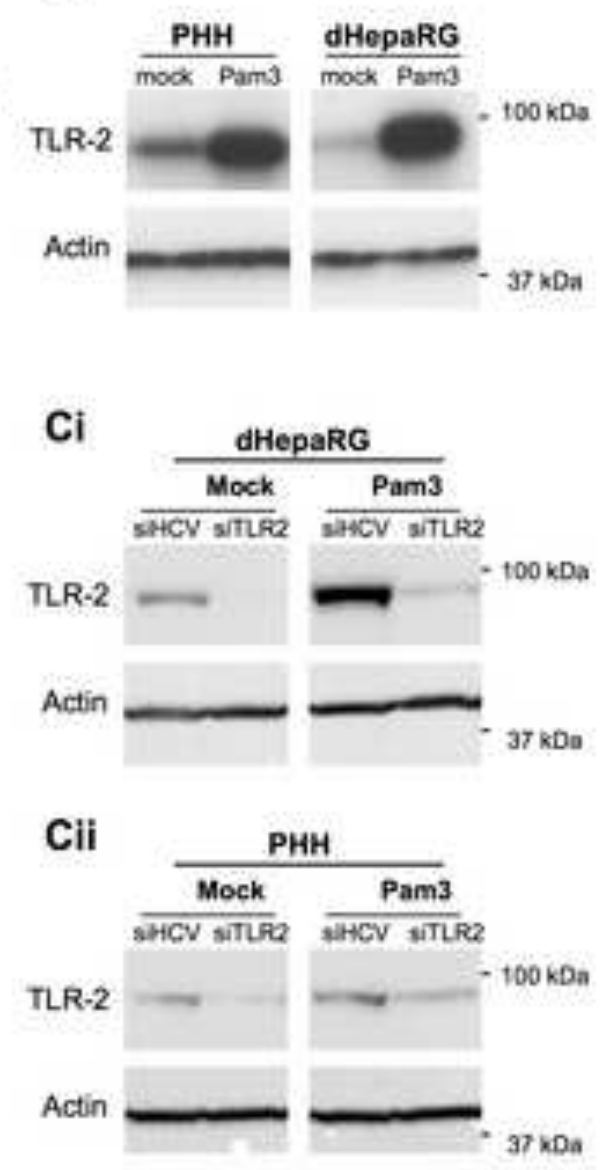
Figure 6

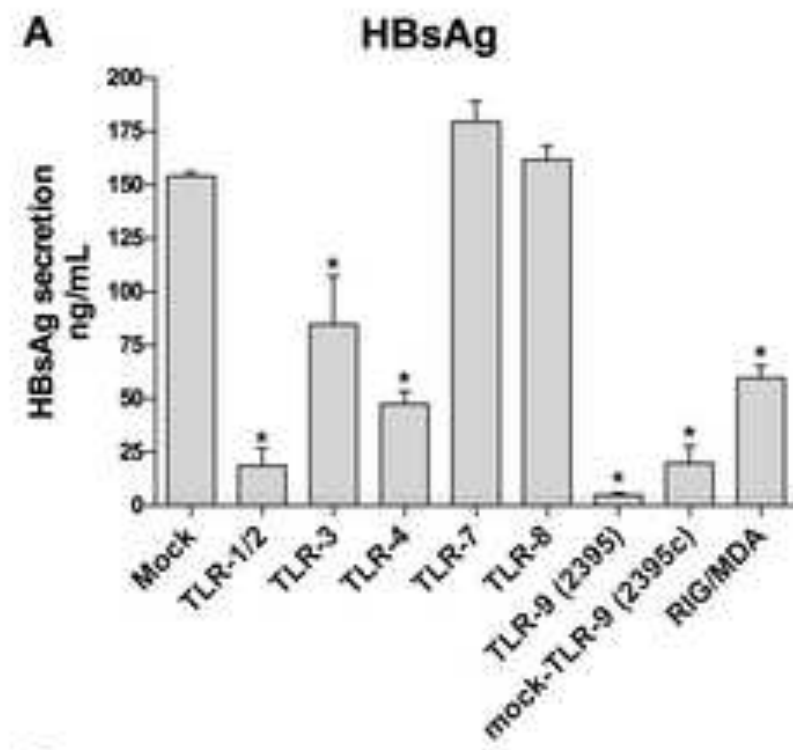

C Intracellular HBV DNA

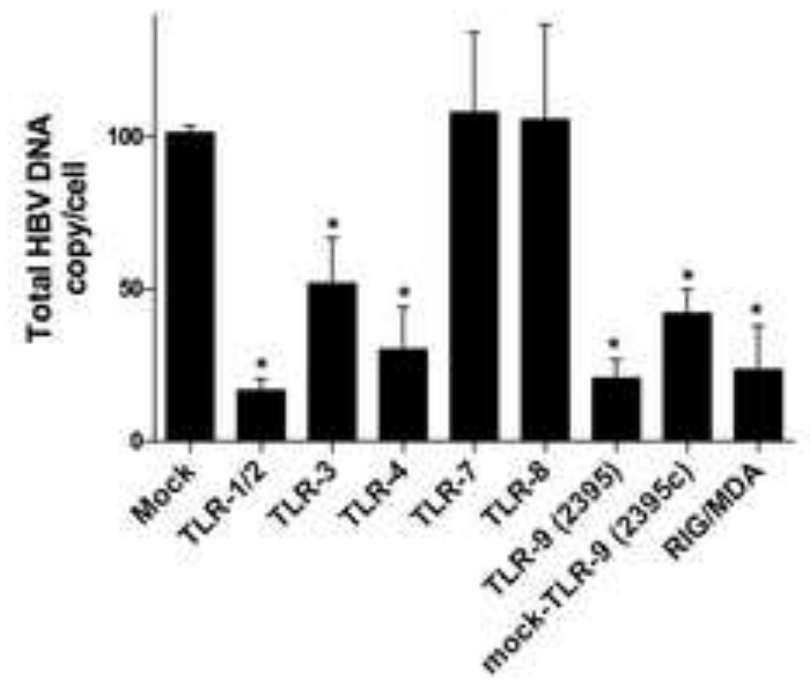

B

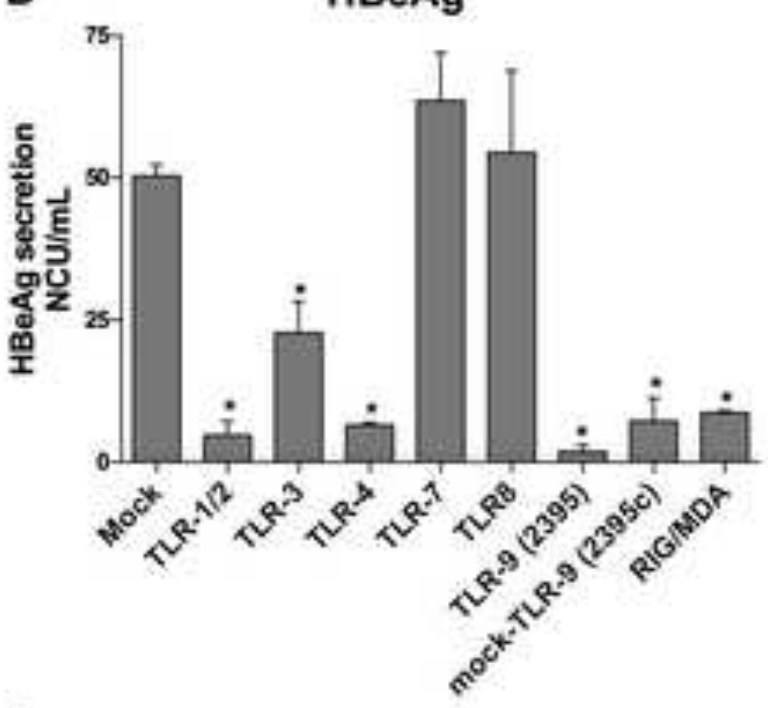

D

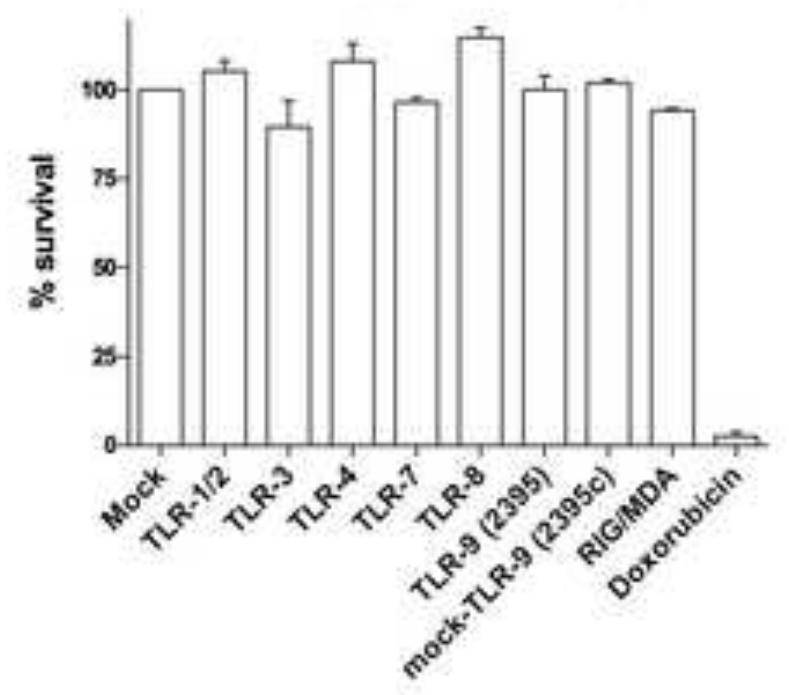


Supplementary material for the manuscript entitled "Expression and Functionality of Toll- and RIG-like receptors in HepaRG Cells" by Luangsay et al. JHEPAT-D-14-01064

\section{Supplementary material and methods}

\section{Analysis of Secreted Type I Interferon}

Two millions of Huh7.5 cells were transfected with $10 \mu \mathrm{g}$ pISRE-Luc vector (Stratagene) in a $10 \mathrm{~cm}$ diameter dish using Mirus TransIT-LT1 transfection reagent according to manufacturer's instructions (Mirus Bio LLC). The pISRE-Luc plasmid (plasmid containing the luciferase gene under the control of the Interferon Stimulated Response Element) expresses luciferase under type-I IFN inducible promoter. After a $16 \mathrm{~h}$ incubation with transfection mixture, cells were trypsinized and reseeded in a 96well plate at approximately $3.10^{4}$ cells/well in a volume of $50 \mu \mathrm{L}$. Six hours later, 50 $\mu \mathrm{L}$ of conditioned HepaRG supernatants, previously stimulated by various ligands at various concentrations as indicated. After $24 \mathrm{~h}$ at $37^{\circ} \mathrm{C}$, cells were washed with phosphate-buffered saline and lysed before luciferase activity was monitored using the Renilla Luciferase Assay System (Promega).

\section{Supplementary figures and figure legends}

Supplementary-Fig. 1. Cyp stainings by FACS and immunofluorescence in differentiated HepaRG. The expression of CYP3A4 (upper panel) and CYP3A1 (lower panel) was assessed by immunofluorescence and FACS in dHepaRG to evaluate the hepato-specificity and the percentage of hepatocyte-lie cells in a monolayer of dHepaRG cells.

Supplementary-Fig. 2. Protein expression of PRR in pHepaRG, dHepaRG and PHH cells. TLR expression analyzed by FACS. Black histograms represent stainings with the indicated TLR antibody, shaded gray histograms represent the isotype control, in pHepaRG, dHepaRG and $\mathrm{PHH}$. 
Supplementary-Fig. 3. Analysis of secreted type-I IFN upon prototypic ligand treatment. Differentiated HepaRG cells were stimulated with increasing doses of PRR ligands (TLR-3 (Poly(l:C)-LMW, 1 and $10 \mu \mathrm{g} / \mathrm{mL}$ ), TLR-4 (LPS, 0.1 and 1 $\mu \mathrm{g} / \mathrm{mL}$ ), TLR-7 (Imiquinod, 10-1-0.1 $\mu \mathrm{g} / \mathrm{mL}$ ), TLR-8 (ssRNA40, 10-2-0.4 $\mu \mathrm{g} / \mathrm{mL}$ ), TLR9 (CpG, 5-1-0.2 $\mu \mathrm{M}$ ), and RIGI/MDA5 (Poly(l:C)-LMH-Lyovec, 0.2 and $1 \mu \mathrm{g} / \mathrm{mL}$ )). Twenty four hours after stimulation, supernatant were tested along with non stimulated cells (NS) for type I interferon activity following procedure described in supplementary materials and methods.

\section{Supplementary Figure 1}
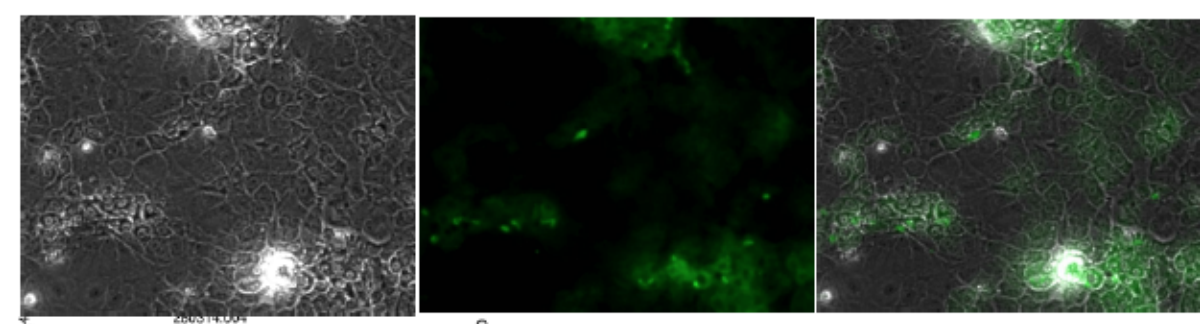

Rabbit CYP3A4 abcam ab135813
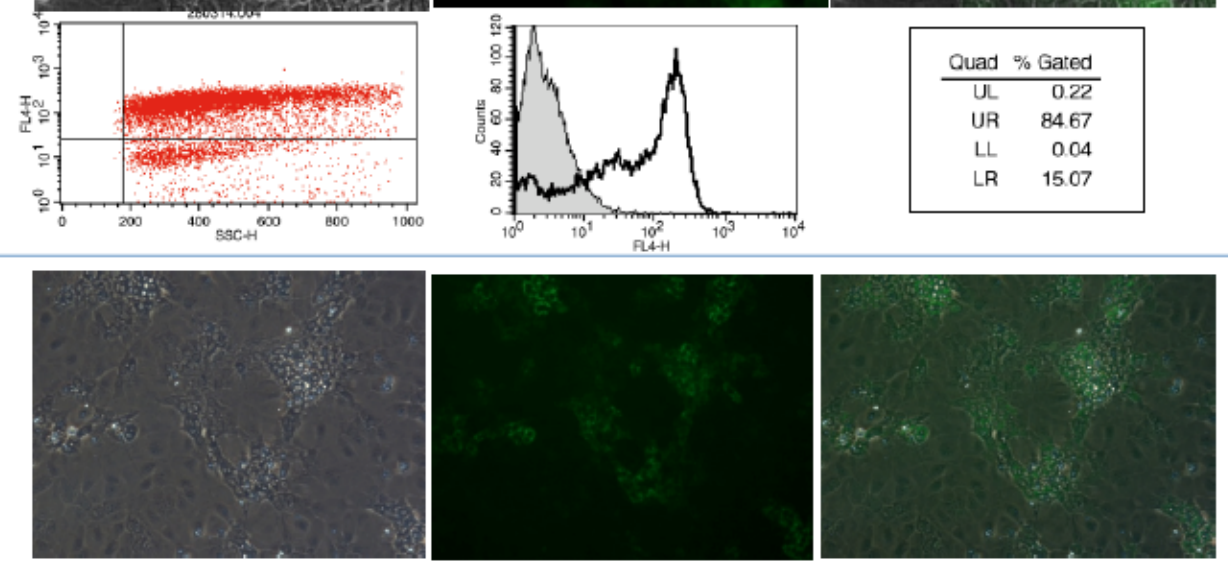

Mouse CYP3A1

Abcam ab22724
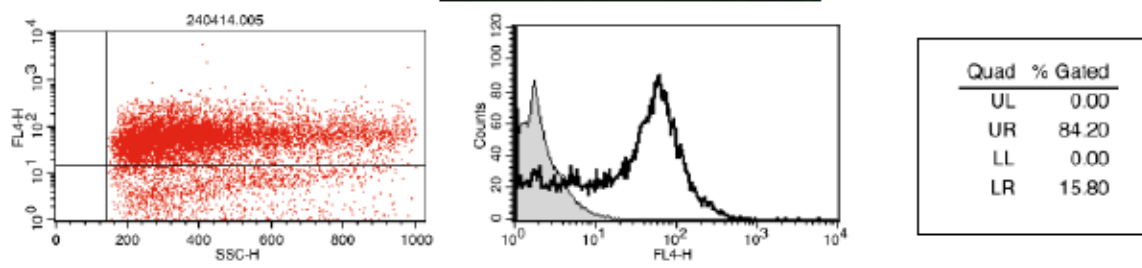


\section{Supplementary Figure 2}

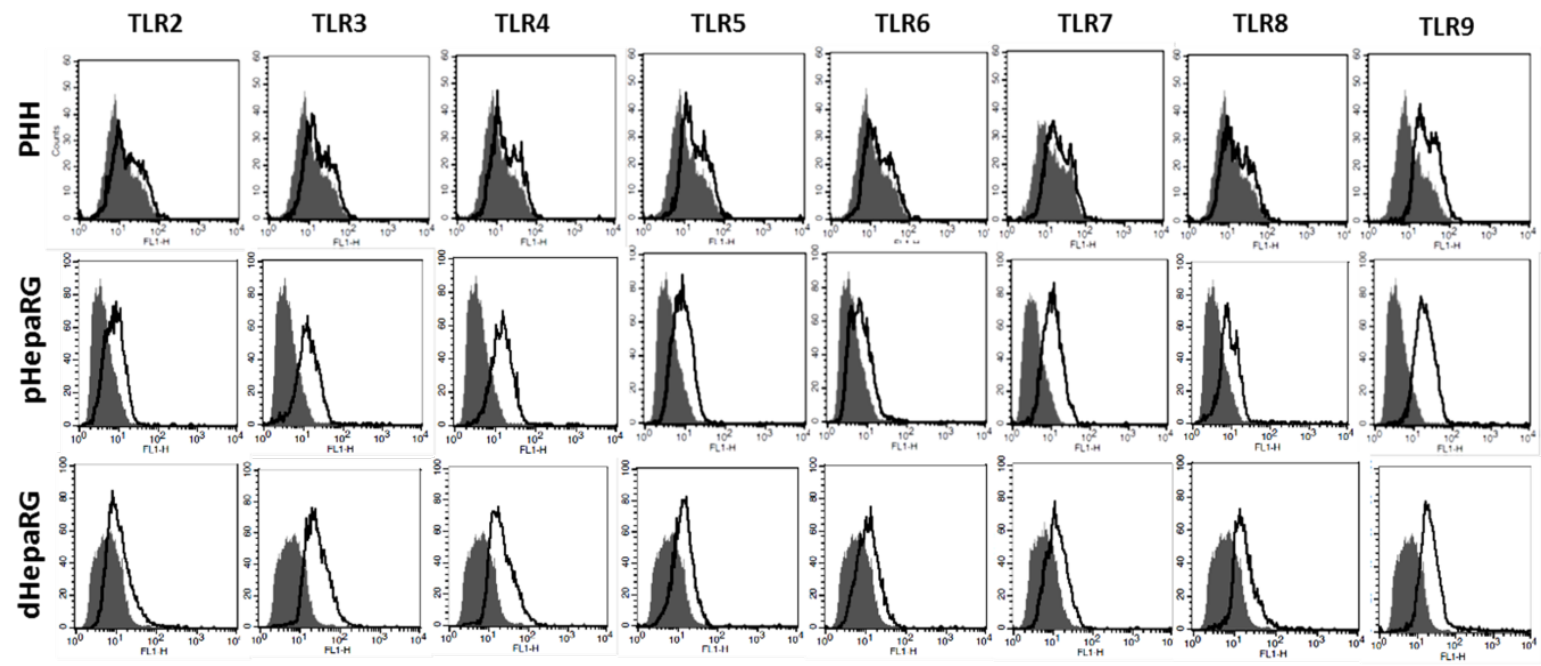

\section{Supplementary Figure 3}

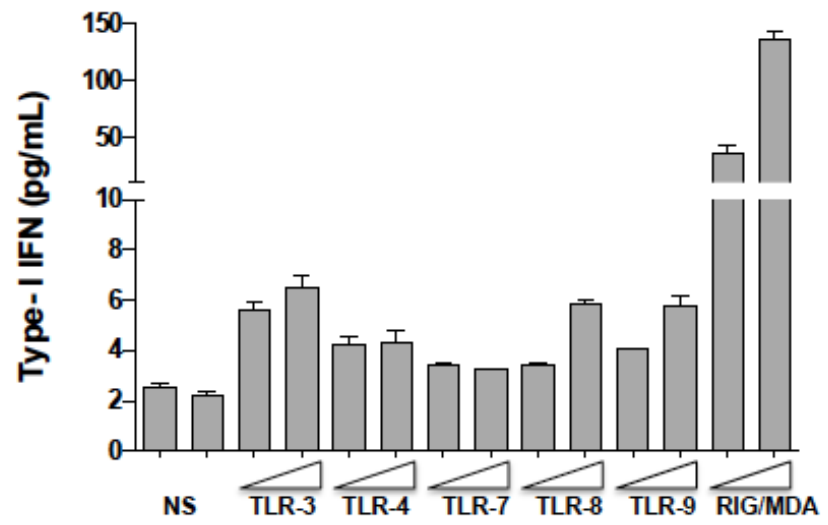

